\title{
FINITE ELEMENT SIMULATION OF NON-ISOTHERMAL POLLUTANT DISPERSION IN URBAN STREET CANYONS USING SHARED MEMORY PARALLELIZATION
}

\author{
D.M.S. Madalozzo ${ }^{1}$, A.L. Braun ${ }^{2}$, A.M. Awruch ${ }^{3}$ \\ ${ }^{1}$ Graduate student, Graduate Program in Civil Engineering (PPGEC), Federal University of \\ Rio Grande do Sul (UFRGS) - deborahmadalozzo@bol.com.br \\ ${ }^{2}$ Professor, Graduate Program in Civil Engineering (PPGEC), Federal University of Rio \\ Grande do Sul (UFRGS) - allbraun@ig.br \\ ${ }^{3}$ Professor, Graduate Program in Civil Engineering (PPGEC), Federal University of Rio \\ Grande do Sul (UFRGS) - amawruch@ufrgs.br
}

\begin{abstract}
A finite element model to simulate pollutant dispersion and thermal effects over the flow field of urban street canyons is presented in this work. Street canyons constitute the basic geometric unit in urban areas, where a narrow passage surrounded by buildings is usually formed. In the street canyons, micro-scale meteorological processes dominate, which are mainly characterized by solar radiation effects and wind-induced flow patterns. Owing to the large amount of pollution emitted from engines of motor vehicles and geometrical configurations of the street canyons, air quality is considerably deteriorated in large cities, having an important impact on human health. In order to evaluate the pollutant dispersion in those areas, field measurements, wind tunnel techniques and numerical simulation have been usually adopted. However, only numerical simulation can efficiently provide results with high spatial/temporal resolution and comprehensive information on the flow field and the pollutant transport. Therefore, a numerical model based on CFD techniques is proposed in this work to simulate incompressible flows considering heat and mass transfer phenomena. In the present model, an explicit two-step Taylor-Galerkin scheme is adopted where the spatial discretization is performed using the finite element method (FEM) with eight-node hexahedral elements, one-point quadrature and hourglass control techniques. The pressure field is explicitly obtained by using the pseudo-compressibility hypothesis and the velocity and temperature fields are coupled by buoyancy forces according to the Boussinesq approximation. Large eddy simulation (LES) is utilized to analyze turbulent flows, where the sub-grid scales are modeled using both, the classical Smagorinsky's model and the dynamic model. Programming techniques for shared memory parallelization are also utilized in order to improve the performance of the present numerical code. Applications reproducing street-canyon configurations are numerically analyzed using a parametric study based on the main parameters utilized to define the flow characteristics.
\end{abstract}

Keywords: Computational Fluid Dynamics (CFD), Finite Element Method (FEM), Pollutant Dispersion, Non-Isothermal Flow, Large Eddy Simulation (LES). 


\section{INTRODUCTION}

The flow field in urban areas is mainly influenced by geometrical and meteorological aspects such as building shape, street width, wind speed and direction, turbulence, solar radiation and photochemical reactions [15]. By analyzing the downtown area of large cities, one can identify a basic geometric configuration composed of long streets laterally confined by medium-rise and high-rise buildings, where the canyon effect is frequently observed. Therefore, experimental and numerical investigations have been performed considering this representative configuration of the urban street geometry, which is commonly defined as urban street canyon [21]. In the street canyons, the wind flow presents shear layer characteristics, with vortices usually generated at the leading edge of the canyon cavity and impingement observed on the trailing edge. In addition, recirculation regions and complex wake structures are also noticed. The urban canopy layer is vertically enclosed by the street surface and the roof level of the surrounding buildings, where microscale meteorological effects are significant. Moreover, large amounts of pollutants are released near the ground from motor vehicles and along the height of the buildings from domestic and industrial exhaust systems. Thermal effects are also observed, which are induced by solar radiation absorbed by building walls and the ground surface. Some comprehensive reviews on street canyon flows may be found in Refs. [27] and [17].

Some methods have been utilized to study the street canyon problem, such as field measurements and wind tunnel experiments (see, for instance, Refs. [13], [22] and [30]). On the other hand, computational fluid dynamics (CFD) has attracted special attention recently owing to significant improvements observed in the field of turbulence modeling and rapid advances verified in processing power and storage capacity of computational systems. Numerical simulations performed with CFD models can provide results with high resolution, where comprehensive information on the flow field can be found from flow variables evaluated at any point of the computational domain and for any instant in time. In addition, problems can be analyzed at full-scale and parametric studies are easily carried out by simply changing geometrical and physical constants that define the numerical model.

LES has been extensively employed in turbulence simulation lately in order to overcome the shortcomings presented by RANS models in street canyon flows. LES is able to calculate a significant range of the flow turbulent scales straightforwardly, while effects of the sub-grid scales over the large scales are approximated using turbulence modeling. The standard Smagorinsky's sub-grid scale (SGS) model [25] has been applied to applications on pollutant dispersion in street canyons, where the empirical constant $\mathrm{C}_{\mathrm{S}}$ (Smagorinsky's constant), which is referred to the SGS eddy viscosity model, is usually set to 0.12. The Smagorinsky's constant can be also evaluated dynamically by using the numerical procedure proposed by Germano et al. [11] and Lilly [18].

In order to investigate the influence of solar radiation, some numerical studies on buoyant flow in street canyons have been carried out in the last decades. In Refs. [24] and [15], flow and pollutant transport in two-dimensional canyon configurations with several aspect ratios are analyzed considering buoyant forces induced by differential heating of the street canyon surfaces. Results demonstrated that wall temperature can significantly influence 
the flow structure and the vertical transport in the street canyon. The same findings were reported by Xie et al. [28] and Xie et al. [29], where RANS and the k- $\varepsilon$ turbulence model were also adopted to analyze two-dimensional canyon configurations. In Ref. [23] numerical predictions are obtained for street canyon flows showing that the urban thermal environment depends on urban geometry when reduced sky view factors and complicated daytime shadow patterns are considered. Street canyon flows with thermal effects were investigated by Baik et al. [2] using a three-dimensional RANS model. LES was initially employed to simulate twodimensional street canyon flows under thermal stratification in the work presented by Ca et al. [6]. LES with two-dimensional formulations were also utilized recently by Li et al. [16] and Cheng and Liu [7] to analyze effects of ground heating and thermal stratification on the pollutant transport in urban canyons.

In the present work, a numerical model is proposed to investigate pollutant dispersion in street canyons with thermal effects. The flow governing equations for street canyon applications are presented and some hypotheses inherent to the problem investigated here are postulated. LES is applied over the governing equations in order to simulate turbulent flows. The filtered equations are obtained and the Reynolds sub-grid tensor is approximated using SGS models. The numerical algorithm for the flow analysis is formulated by applying the TaylorGalerkin method over the governing equations, where the FEM is adopted. Spatial discretization is performed employing eight-node hexahedral elements with one-point quadrature, such that element matrices can be evaluated analytically. An explicit two-step scheme is utilized to solve the flow governing equations in the time domain. Programming techniques for shared memory parallelization are utilized in order to improve the performance of the present numerical code. Some investigations are performed to validate the present formulation by determining flow fields and pollutant dispersion in street canyons, where different configurations are analyzed and thermal effects are simulated. A realistic problem of pollutant dispersion in urban canyons with street intersections is also proposed.

\section{MODEL DESCRIPTION}

\subsection{Flow and transport equations}

The flow problem in urban street canyons is mathematically described using balance equations for momentum, mass and energy, and the scalar transport equation for pollutant species. Some hypothesis may be considered in order to simplify the general formulation. In the present work, the same assumptions adopted by Braun and Awruch [5] to characterize wind flows are utilized and additional hypotheses are also specified regarding the pollutant transport. The main postulates assumed in the present model may be summarized as follows:

(a) Wind flows are assumed to be incompressible;

(b) The air density is assumed to be constant;

(c) Air density variations due to temperature effects are considered only in terms of buoyancy forces acting in the momentum equations; 
(d) Pollutant species are assumed to be mechanically passive and chemically inert;

(e) The Newtonian fluid model is adopted for constitutive description of the air.

The governing equations are kinematically described using the classical Eulerian approach and the mass balance equation is written here according to the pseudo-compressibility hypothesis proposed by Chorin [8], which leads to flow formulations where the pressure field is obtained explicitly. Considering the Cartesian coordinate system, the flow governing equations for street canyon flows may be presented as follows:

Momentum equations - the Navier-Stokes equations:

$$
\frac{\partial v_{i}}{\partial t}+v_{j} \frac{\partial v_{i}}{\partial x_{j}}=\frac{1}{\rho}\left(\frac{\partial \sigma_{i j}}{\partial x_{j}}+S_{i}\right) \quad(\mathrm{i}, \mathrm{j}=1,2,3) \quad \text { in } \Omega
$$

Mass conservation equation - the pseudo-compressibility form:

$$
\frac{\partial p}{\partial t}+v_{j} \frac{\partial p}{\partial x_{j}}+\rho c_{s}^{2} \frac{\partial v_{j}}{\partial x_{j}}=0 \quad(\mathrm{j}=1,2,3) \quad \text { in } \Omega
$$

Energy conservation equation:

$$
\frac{\partial T}{\partial t}+v_{j} \frac{\partial T}{\partial x_{j}}=\frac{1}{\rho c_{v}}\left(k \frac{\partial^{2} T}{\partial x_{j}^{2}}+\rho S_{T}\right) \quad(\mathrm{j}=1,2,3) \quad \text { in } \Omega
$$

Pollutant transport equation:

$$
\frac{\partial c}{\partial t}+v_{j} \frac{\partial c}{\partial x_{j}}=D \frac{\partial^{2} c}{\partial x_{j}^{2}}+S_{c} \quad(\mathrm{j}=1,2,3) \quad \text { in } \Omega
$$

where $v_{i}$ and $S_{\mathrm{i}}$ are components of the vectors of flow velocity and body force, respectively, which are given according to the direction of the Cartesian axes $x_{i}, p$ is the thermodynamic pressure, $T$ is the temperature and $c$ is the pollutant concentration. The source terms for temperature and pollutant are denoted by $S_{T}$ and $S_{C}$, respectively. The fluid properties are given by the fluid density $\rho$, the constant of isotropic thermal conductivity $k$, the constant of isotropic pollutant diffusion $D$, the specific heat at constant volume $c_{v}$ and the sound speed in the flow field $c_{s}$. The governing equations are valid for a spatial domain $\Omega$ and a time interval $\left[t_{0}\right.$, $t$, where $t_{0}$ is the initial time, when initial conditions for the flow variables must be defined.

The components of the fluid stress tensor $\sigma$ are obtained considering the Newtonian constitutive equation for a viscous fluid in conjunction with the Stokes hypothesis, which leads to:

$$
\sigma_{i j}=-p \delta_{i j}+\mu\left(\frac{\partial v_{i}}{\partial x_{j}}+\frac{\partial v_{j}}{\partial x_{i}}\right)+\lambda \frac{\partial v_{k}}{\partial x_{k}} \delta_{i j}
$$

where $\mu$ and $\lambda$ are the dynamic and bulk viscosities of the fluid, respectively, and $\delta_{\mathrm{ij}}$ denotes the components of the Kroenecker's delta $\left(\delta_{i j}=1\right.$ for $\mathrm{i}=\mathrm{j} ; \delta_{\mathrm{ij}}=0$ for $\left.\mathrm{i} \neq \mathrm{j}\right)$.

Incompressible flows under thermal effects are generally analyzed using the Boussinesq's approximation, where density variations are considered in terms of body forces. By including effects of concentration, a general buoyancy force may be described as follows: 


$$
S_{i}=-\rho g_{i}\left[\beta\left(T-T_{0}\right)+\beta_{C}\left(C-C_{0}\right)\right]
$$

where $\beta$ is the coefficient of volumetric expansion due to thermal effects, $\beta_{C}$ is the coefficient of volumetric expansion due to concentration variation, $g_{i}$ are the components of the vector of gravity acceleration, which are given according to the direction of the Cartesian axes $x_{i}$, and $T_{0}$ and $C_{0}$ are reference values for temperature and concentration, which are usually associated with undisturbed regions of the flow field. In the present work, the influence of concentration variations over the fluctuating gravitational forces (Eq. 6) is disregarded.

In order to solve the system of governing equations, initial conditions for the flow variables must be specified. In addition, the following boundary conditions must be also imposed over the spatial domain where the problem takes place:

$$
\begin{array}{cc}
v_{i}=\bar{v}_{i} & \text { on } \Gamma^{\mathrm{v}} \\
p=\bar{p} & \text { on } \Gamma^{\mathrm{p}} \\
T=\bar{T} & \text { on } \Gamma^{\mathrm{T}} \\
C=\bar{C} & \text { on } \Gamma^{\mathrm{C}} \\
t_{i}=\frac{1}{\rho} \sigma_{i j} n_{j} & \text { on } \Gamma^{\sigma} \\
q=\frac{k}{\rho c_{v}} \frac{\partial T}{\partial x_{j}} n_{j} & \text { on } \Gamma^{\mathrm{q}} \\
J=D \frac{\partial C}{\partial x_{j}} n_{j} & \text { on } \Gamma^{J}
\end{array}
$$

where Eqs. (7-10) represent Dirichlet boundary conditions for velocity, pressure, temperature and pollutant concentration, respectively, which are imposed on the respective boundary regions $\Gamma^{\mathrm{v}}, \Gamma^{\mathrm{p}}, \Gamma^{\mathrm{T}}$ and $\Gamma^{\mathrm{C}}$ of the spatial domain $\Omega$. The respective prescribed values are defined by overbars on the right-hand side of the respective equations. Equations (11-13) are associated with Neumann boundary conditions for the balance and transport equations. Equation (11) denotes traction components defined according to the Cartesian directions $x_{i}$ and imposed on the boundary region $\Gamma^{\sigma}$. Equations (12) and (13) indicate fluxes of heat and pollutant through the boundary regions $\Gamma^{\mathrm{q}}$ and $\Gamma^{\mathrm{J}}$, respectively. In Eq. (11), $n_{j}$ are components of the unit normal vector at a point located on the boundaries $\Gamma^{\sigma}, \Gamma^{\mathrm{q}}$ or $\Gamma^{J}$.

\subsection{Turbulence modeling - LES}

The basic step in the LES approach is the spatial filtering procedure performed over the flow variables, which are decomposed into components referring to large and sub-grid scales. Considering a general flow variable denoted by $\phi$, the filtering operation can be mathematically described as the convolution of $\phi$ with a kernel $G$ representing the filter function, that is:

$$
\bar{\phi}\left(x_{i}, t\right)=\int_{\Omega} \phi\left(r_{i}, t\right) G\left(x_{i}-r_{i}, t\right) d r_{i}
$$


where $\bar{\phi}$ is the large scale component of $\phi$, such that $\phi=\bar{\phi}+\phi^{\prime}$, where $\phi^{\prime}$ is the sub-grid component of $\phi$. The spatial field where the filtering operation takes place is indicated by $\Omega$. For a box filter, the kernel function is defined by (see, for instance, Ref. [10]):

$$
G\left(x_{i}-r_{i}, t\right)=\left\{\begin{array}{ll}
\prod_{i=1}^{n} \frac{1}{\bar{\Delta}_{i}} & \text { if }\left|x_{i}-r_{i}\right| \leq \frac{\bar{\Delta}_{i}}{2} \\
0 & \text { if }\left|x_{i}-r_{i}\right|>\frac{\bar{\Delta}_{i}}{2}
\end{array} \quad(\mathrm{i}=1, \mathrm{n})\right.
$$

where $\bar{\Delta}_{i}$ is the filter width in the $i$-th Cartesian direction and $n$ is the number of dimensions of the filter operator.

By applying the filtering procedure (Eq. 14) over the flow governing equations (Eqs. 1-4), the advective terms lead to the SGS terms. The term involving SGS interactions in the momentum equations is referred to as SGS Reynolds stress tensor. The components of the SGS Reynolds stress tensor are usually defined as:

$$
\sigma_{i j}^{S G S}=\rho \overline{v_{i}^{\prime} v_{j}^{\prime}}
$$

In order to close the mathematical problem, the deviatoric part of the SGS Reynolds stress tensor is approximated using the Boussinesq eddy viscosity model as follows:

$$
\tau_{i j}^{S G S}=\sigma_{i j}^{S G S}-\frac{1}{3} \sigma_{k k}^{S G S} \delta_{i j}=\sigma_{i j}^{S G S}-\frac{2}{3} \bar{E}_{k} \delta_{i j} \quad \Rightarrow \quad \tau_{i j}^{S G S}=-2 v_{t} \bar{S}_{i j}
$$

where $\bar{E}_{k}$ is the SGS turbulent kinetic energy, $v_{t}$ is the kinematic eddy viscosity and $\bar{S}_{i j}$ are the components of the strain rate tensor defined in terms of the large scale components of the velocity field, that is:

$$
\bar{S}_{i j}=\frac{1}{2}\left(\frac{\partial \bar{v}_{i}}{\partial x_{j}}+\frac{\partial \bar{v}_{j}}{\partial x_{i}}\right)
$$

The SGS terms in the heat and pollutant transport equations denote SGS turbulent fluxes of heat and pollutant, respectively, which may be written as:

$$
\begin{gathered}
-c_{p} \overline{v_{j}^{\prime} T^{\prime}}=k_{t} \frac{\partial \bar{T}}{\partial x_{j}}=\frac{v_{t}}{\operatorname{Pr}_{t}} \frac{\partial \bar{T}}{\partial x_{j}} \\
-\overline{v_{j}^{\prime} C^{\prime}}=D_{t} \frac{\partial \bar{C}}{\partial x_{j}}=\frac{v_{t}}{\mathrm{Sc}_{t}} \frac{\partial \bar{C}}{\partial x_{j}}
\end{gathered}
$$

where $k_{t}$ and $D_{t}$ are the turbulent diffusivity coefficients for the heat and pollutant transport equations. These SGS terms are obtained using the eddy diffusivity assumption, where the turbulent Prandlt number $\mathrm{Pr}_{\mathrm{t}}$ and the turbulent $\mathrm{Schmidt}$ number $\mathrm{Sc}_{\mathrm{t}}$ are utilized. Owing to the lack of physical meaning, the SGS terms in the mass conservation equation are disregarded in the present formulation. Consequently, the final form of the filtered governing equations, considering the eddy viscosity approach for the SGS terms, may be presented as follows:

$$
\frac{\partial \bar{v}_{i}}{\partial t}+\bar{v}_{j} \frac{\partial \bar{v}_{i}}{\partial x_{j}}=-\frac{1}{\rho} \frac{\partial \bar{p}}{\partial x_{i}}+\frac{\partial}{\partial x_{j}}\left[2\left(v+v_{t}\right) \bar{S}_{i j}+\frac{\lambda}{\rho} \frac{\partial \bar{v}_{k}}{\partial x_{k}}\right]+\frac{1}{\rho} \bar{S}_{i} \quad(\mathrm{i}, \mathrm{j}, \mathrm{k}=1,2,3) \quad \text { in } \Omega
$$




$$
\begin{array}{cc}
\frac{\partial \bar{p}}{\partial t}+\bar{v}_{j} \frac{\partial \bar{p}}{\partial x_{j}}+\rho c_{s}^{2} \frac{\partial \bar{v}_{j}}{\partial x_{j}}=0 \quad(\mathrm{j}=1,2,3) \quad \text { in } \Omega & \\
\frac{\partial \bar{T}}{\partial t}+\bar{v}_{j} \frac{\partial \bar{T}}{\partial x_{j}}=\frac{\partial}{\partial x_{j}}\left[\left(\frac{k}{\rho c_{p}}+\frac{v_{t}}{\operatorname{Pr}_{t}}\right) \frac{\partial \bar{T}}{\partial x_{j}}\right]+\frac{1}{c_{p}} \bar{S}_{T} \quad(\mathrm{j}=1,2,3) \quad \text { in } \Omega \\
\frac{\partial \bar{C}}{\partial t}+\bar{v}_{j} \frac{\partial \bar{C}}{\partial x_{j}}=\frac{\partial}{\partial x_{j}}\left[\left(D+\frac{v_{t}}{\mathrm{Sc}_{t}}\right) \frac{\partial \bar{C}}{\partial x_{j}}\right]+\bar{S}_{C} \quad(\mathrm{j}=1,2,3) \quad \text { in } \Omega
\end{array}
$$

Smagorinsky [25] proposed to relate the eddy viscosity to the large scale flow field and the size of the numerical grid by using the following expression:

$$
v_{t}=\left(C_{S} \bar{\Delta}\right)^{2}|\overline{\mathbf{S}}|
$$

where $\bar{\Delta}$ is the characteristic filter width, which may be locally obtained from the element volume in FEM formulations $\left(\bar{\Delta}=\sqrt[3]{\bar{\Delta}_{1} \cdot \bar{\Delta}_{2} \cdot \bar{\Delta}_{3}}\right),|\overline{\mathbf{S}}|$ is the modulus of the strain rate tensor and $C_{S}$ is an empiric constant known as Smagorinsk's constant, with values usually ranging from 0.1 to 0.25 . However, it is observed that $C_{S}$ is not a universal constant, but it is flow dependent. In order to eliminate this shortcoming, the eddy viscosity $v_{t}$ can be also obtained employing the dynamic sub-grid scale model developed by Germano et al. [11] and Lilly [18], which may be expressed as:

$$
v_{\mathrm{t}}=C(\vec{x}, t) \bar{\Delta}^{2}|\overline{\mathbf{S}}|
$$

where $C(\vec{x}, t)$ is the dynamic coefficient, with $\vec{x}$ and $t$ indicating space and time dependencies. The dynamic coefficient is updated along the time integration process taking into account instantaneous conditions of the flow field, that is:

$$
C(\vec{x}, t)=-\frac{1}{2} \frac{L_{i j} M_{i j}}{M_{i j} M_{i j}}
$$

where:

$$
L_{i j}=\left\langle\bar{v}_{i} \bar{v}_{j}\right\rangle-\left\langle\bar{v}_{i}\right\rangle\left\langle\bar{v}_{j}\right\rangle
$$

and:

$$
M_{i j}=\langle\bar{\Delta}\rangle^{2}|\langle\bar{S}\rangle|\left\langle\bar{S}_{i j}\right\rangle-\left\langle\bar{\Delta}^{2}|\bar{S}| \bar{S}_{i j}\right\rangle
$$

Nevertheless, the solution of Eq. (27) requires two filtering procedures on the flow governing equations: the first filtering is associated with the use of the LES formulation, where the spatial filter $\bar{\Delta}$ is applied in order to define the large scale variables $\bar{\phi}$; the second filtering is referred to another filter called test filter $\langle\bar{\Delta}\rangle$, which must be larger than the width of the first spatial filter $\bar{\Delta}$. Filtered variables related to the second spatial filter are evaluated here using the following expression (see Fig. 1):

$$
\langle\bar{\phi}\rangle^{\mathrm{i}}=\sum_{\mathrm{j}=1}^{\mathrm{n}}\left(\frac{\bar{\phi}^{\mathrm{j}}}{d_{\mathrm{i}}^{\mathrm{j}}}\right) / \sum_{\mathrm{j}=1}^{\mathrm{n}}\left(\frac{1}{d_{\mathrm{i}}^{\mathrm{j}}}\right)
$$


where $\langle\bar{\phi}\rangle^{\mathrm{i}}$ is the filtered value of $\bar{\phi}$ at the nodal point $i, n$ is the number of nodal points having direct connectivity with the nodal point $i, d_{\mathrm{i}}^{\mathrm{j}}$ is the Euclidean distance between the nodal points $i$ and $j$ and $\bar{\phi}^{j}$ is the filtered value of the variable $\phi$ at the nodal point $j$, considering the first filtering procedure. The characteristic dimension of the second filter may be defined as $\langle\bar{\Delta}\rangle=2 * \bar{\Delta}$ for regularly spaced grids.

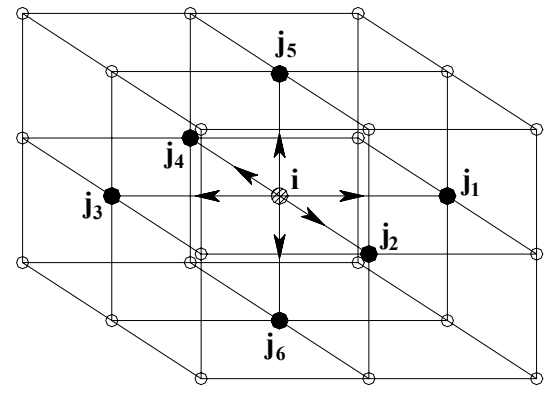

Figure 1. Second filter arrangement.

\subsection{Numerical model}

The numerical model for the flow analysis is formulated considering the two-step Taylor-Galerkin model proposed by Kawahara and Hirano [14], where the governing equations are temporally discretized using Taylor series expansions over time derivative terms. The Bubnov-Galerkin method is then applied on the time discrete form of the governing equations and the FEM formulation is introduced.

A generic flow variable $\vartheta(\vec{x}, t)$, where $\vec{x}=\left(x_{1}, x_{2}, x_{3}\right)$ indicates the Cartesian coordinates of a material point in the spatial field $\Omega$ and $t$ denotes the time domain, can be expanded over the time interval $\Delta t$ by using Taylor series as follows:

$$
\vartheta(\vec{x}, t+\Delta t)=\vartheta(\vec{x}, t)+\Delta t \frac{\partial}{\partial t} \vartheta(\vec{x}, t)+\frac{\Delta t^{2}}{2 !} \frac{\partial^{2}}{\partial t^{2}} \vartheta(\vec{x}, t)
$$

This equation is considered in the present model in order to define the time marching scheme for flow velocity, pressure, temperature and pollutant concentration. The first and second order time derivatives observed in Eq (31) are obtained from the system of governing equations by using the Lax-Wendroff method. The time marching scheme for $\vartheta(\vec{x}, t)$ can be expressed as follows:

$$
\vartheta^{n+1}=\vartheta^{n}+\Delta \vartheta^{n+1 / 2}
$$

where $n=t$ and $n+1=t+\Delta t$. The second term on the right-hand side of Eq. (32) indicates the flow variables must be evaluated at the intermediate point of the time interval $\Delta t$. Hence, the two-step scheme can provide a second order approximation in time, where the first step consists in determining the flow variables at $n+1 / 2$ and the second step is responsible for updating the flow variables considering increments calculated with variables evaluated in the first step. The flow variables at $n+1 / 2$ are obtained employing a Taylor series expansion over $\Delta t / 2$, which may be written in terms of $\vartheta(\vec{x}, t)$ as follows: 


$$
\vartheta(\vec{x}, t+\Delta t / 2)=\vartheta(\vec{x}, t)+\frac{\Delta t}{2} \frac{\partial}{\partial t} \vartheta(\vec{x}, t)+\frac{(\Delta t / 2)^{2}}{2 !} \frac{\partial^{2}}{\partial t^{2}} \vartheta(\vec{x}, t)
$$

Higher order approximations are obtained for the advective terms of the governing equations when Eqs. (31) and (33) are adopted. These additional terms form the balancing tensor diffusivity (BTD) and represent an artificial viscosity, which is usually required to stabilize numerical simulations for convective dominated flows. An algorithm describing the numerical scheme utilized here to solve the governing equations may be found in Table 1.

The time interval used in the time discretization scheme is restricted by the Courant condition in order to maintain numerical stability, since the time integration is carried out explicitly. A critical value can be calculated at element level by using the following expression:

$$
\Delta t_{\mathrm{E}}=\alpha \frac{\Delta x_{\mathrm{E}}}{\mathrm{V}_{\mathrm{E}}+c} \quad \mathrm{E} \in[1, N E]
$$

where $\Delta x_{E}$ is the characteristic width of element $E, V_{E}$ is a characteristic flow speed of element $E, c_{s}$ is the sound speed in the flow field, $\alpha$ is a safety constant, which is generally less than unity, and $N E$ is the number of elements in the finite element mesh. Although independent time steps can be adopted for each element of the finite element mesh, the time step employed in the numerical applications carried out in this work is obtained from the smaller time step calculated with Eq. (34).

The Bubnov-Galerkin method is applied on the discrete governing equations (see Table 1), where finite element approximations for the spatial and variable fields are performed considering the eight-node hexahedral element formulation and the one-point quadrature technique. Consequently, the element matrices can be analytically evaluated at the origin of the parametric space $\left(\xi_{1}=\xi_{2}=\xi_{3}=0\right)$. This integration technique leads to exact evaluation of element matrices for elements with parallel faces. Good results can be also obtained for slightly distorted elements, but they are not strictly exact. In the present work, the hourglass control scheme proposed by Christon [9] is utilized in order to suppress spurious modes, which is based on h-stabilization. Further information on hourglass instability may be obtained in Belytschko et al. [3] and a detailed description of the numerical model adopted here is found in Braun [4] and Madalozzo [20].

Table 1. Numerical algorithm for the flow analysis.

1) The first step: calculate the flow variables at the intermediate point of the time increment:

$$
\begin{aligned}
& v_{i}^{n+1 / 2}=v_{i}^{n}+\frac{\Delta t}{2}\left\{-v_{j} \frac{\partial v_{i}}{\partial x_{j}}-\frac{1}{\rho} \frac{\partial p}{\partial x_{j}} \delta_{i j}+\frac{\partial}{\partial x_{j}}\left[\left(v+v_{t}\right)\left(\frac{\partial v_{i}}{\partial x_{j}}+\frac{\partial v_{j}}{\partial x_{i}}\right)+\frac{\lambda}{\rho} \frac{\partial v_{k}}{\partial x_{k}} \delta_{i j}\right]+\left(\frac{\Delta t}{4} v_{j} v_{k}\right) \frac{\partial^{2} v_{i}}{\partial x_{j} x_{k}}+\frac{S_{i}}{\rho}\right\}^{n} \\
& p^{n+1 / 2}=p^{n}+\frac{\Delta t}{2}\left\{\left[-v_{j} \frac{\partial p}{\partial x_{j}}-\rho c^{2} \frac{\partial v_{j}}{\partial x_{j}}\right]+\left(\frac{\Delta t}{4} v_{i} v_{j}\right) \frac{\partial^{2} p}{\partial x_{j} \partial x_{i}}\right\}^{n} \\
& T^{n+1 / 2}=T^{n}+\frac{\Delta t}{2}\left\{-v_{j} \frac{\partial T}{\partial x_{j}}+\left(\frac{k}{\rho c_{p}}+\frac{v_{t}}{\operatorname{Pr}_{t}}\right) \frac{\partial^{2} T}{\partial x_{j}^{2}}+\left(\frac{\Delta t}{4} v_{i} v_{j}\right) \frac{\partial^{2} T}{\partial x_{j} \partial x_{i}}+\frac{1}{c_{p}} S_{T}\right\}^{n}
\end{aligned}
$$


$C^{n+1 / 2}=C^{n}+\frac{\Delta t}{2}\left\{-v_{j} \frac{\partial C}{\partial x_{j}}+\left(D+\frac{v_{t}}{\mathrm{Sc}_{t}}\right) \frac{\partial^{2} C}{\partial x_{j}^{2}}+\left(\frac{\Delta t}{4} v_{i} v_{j}\right) \frac{\partial^{2} C}{\partial x_{j} \partial x_{i}}+S_{C}\right\}^{n}$

2) Apply the boundary conditions on $v_{i}^{n+1 / 2}, p^{n+1 / 2}, T^{n+1 / 2}$ and $C^{n+1 / 2}$ (see Eqs. 7 to 13).

3) Calculate the pressure increment $\Delta p^{n+1 / 2}=p^{n+1 / 2}-p^{n}$.

4) Calculate the corrected velocity field with the updated pressure $\Delta p^{n+1 / 2}$ :

$v_{i}^{n+1 / 2}=v_{i}^{n+1 / 2}-\frac{1}{\rho} \frac{\Delta t^{2}}{8} \frac{\partial \Delta p^{n+1 / 2}}{\partial x_{i}}$

5) Apply the boundary condition on $v_{i}^{n+1 / 2}$ (see Eq. 7).

6) The second step: update the flow variables at the end of the time increment:

$v_{i}^{n+1}=v_{i}^{n}+\Delta v_{i}^{n+1 / 2}$

$p^{n+1}=p^{n}+\Delta p^{n+1 / 2}$

$T^{n+1}=T^{n}+\Delta T^{n+1 / 2}$

$C^{n+1}=C^{n}+\Delta C^{n+1 / 2}$

where:

$$
\begin{aligned}
& \Delta v_{i}^{n+1 / 2}=\Delta t\left\{-v_{j} \frac{\partial v_{i}}{\partial x_{j}}-\frac{1}{\rho} \frac{\partial p}{\partial x_{j}} \delta_{i j}+\frac{\partial}{\partial x_{j}}\left[\left(v+v_{t}\right)\left(\frac{\partial v_{i}}{\partial x_{j}}+\frac{\partial v_{j}}{\partial x_{i}}\right)+\frac{\lambda}{\rho} \frac{\partial v_{k}}{\partial x_{k}} \delta_{i j}\right]+\frac{S_{i}}{\rho}\right\}^{n+1 / 2} \\
& \Delta p^{n+1 / 2}=\Delta t\left\{-v_{j} \frac{\partial p}{\partial x_{j}}-\rho c^{2}\left(\frac{\partial v_{j}}{\partial x_{j}}\right)\right\}^{n+1 / 2} \\
& \Delta T^{n+1 / 2}=\Delta t\left\{-v_{j} \frac{\partial T}{\partial x_{j}}+\left(\frac{k}{\rho c_{p}}+\frac{v_{t}}{\operatorname{Pr}_{t}}\right) \frac{\partial^{2} T}{\partial x_{j}^{2}}+\frac{1}{c_{p}} S_{T}\right\}^{n+1 / 2} \\
& \Delta C^{n+1 / 2}=\Delta t\left\{-v_{j} \frac{\partial C}{\partial x_{j}}+\left(D+\frac{v_{t}}{\mathrm{Sc}_{t}}\right) \frac{\partial^{2} C}{\partial x_{j}^{2}}+\frac{1}{c_{p}} S_{C}\right\}^{n+1 / 2}
\end{aligned}
$$

7) Apply the boundary conditions on $v_{i}^{n+1}, p^{n+1}, T^{n+1}$ and $C^{n+1}$.

8) Return to 1) for the next time step.

\section{NUMERICAL APPLICATIONS}

\subsection{Pollutant dispersion in two-dimensional street canyon models}

This first application is dedicated to evaluate the pollutant dispersion in idealized street-canyon configurations, which are utilized in order to validate the present numerical model for street canyon flows involving mass and heat transport. Investigations are carried out considering street canyons with unit aspect ratio (height/width $-\mathrm{H} / \mathrm{W}=1$ ), where isothermal conditions and wall temperature effects are analyzed. Figure 1 shows a schematic drawing of the street canyon model containing geometric information on the computational space and the boundary conditions adopted. Notice that no-slip boundary conditions are im- 
posed on the street canyon surfaces. In the same figure, the finite element mesh employed in the present simulations is also presented. The spatial field is discretized using 68400 eightnode hexahedral elements where the smaller elements are found near the canyon walls with $\Delta x_{E}=0.085 \mathrm{~m}$ (see Eq. 34). The canyon cavity was discretized using $120 \mathrm{x} 120$ elements. The computational domain utilized here follows the geometric configuration proposed by Kim and Baik [15], which presents a pollutant emitted from a point source located at the bottom of the canyon (see Fig. 1). The emission rate utilized here is $S_{C}=0.01 \mathrm{~m}^{3} / \mathrm{s}$. For the non-isothermal analyses, boundary conditions with constant temperature of $\mathrm{T}=1$ are applied separately on the upwind building wall, the downwind building wall and the bottom of the canyon.

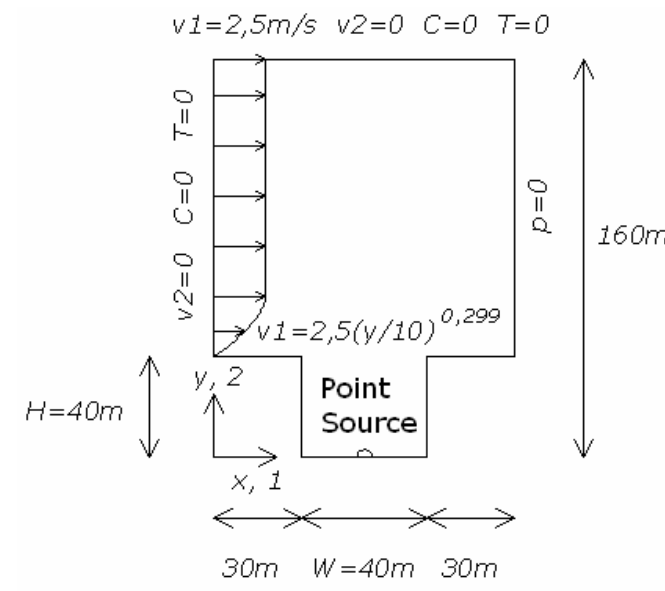

(a)

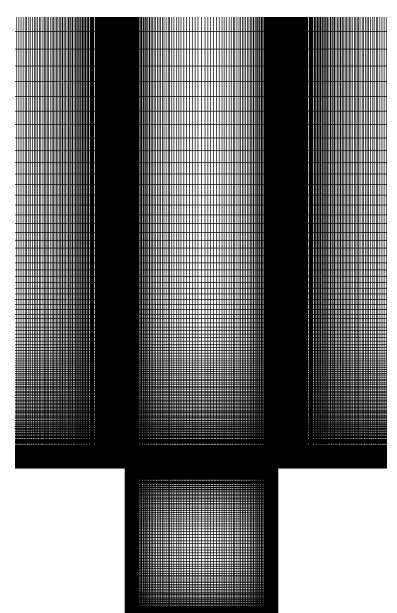

(b)

Figure 1. Two-dimensional street canyon: (a) computational domain; (b) finite element mesh.

Flow properties adopted by the numerical model proposed here are found in Table 2. The flow variables are started with zero initial conditions, where the time step is chosen taking into account Eq. 34 with $\alpha=0.215$, which leads to $\Delta \mathrm{t}=0.001 \mathrm{~s}$. Turbulence is simulated considering LES and the classical Smagorisky's model is employed for sub-grid scale modeling, where $\mathrm{C}_{\mathrm{S}}=0.12$ is utilized. The Reynolds number is calculated in this case considering the height $(\mathrm{H})$ of the street canyon and the undisturbed flow velocity at $\mathrm{y}=160 \mathrm{~m}$, i.e. $\mathrm{V}_{\infty}=$ $2.5 \mathrm{~m} / \mathrm{s}$. The time integration was performed up to $\mathrm{t}=3600 \mathrm{~s}$ and time average fields were obtained over the last $600 \mathrm{~s}$ of the numerical analysis.

In Fig. 2 results related to time average streamline fields obtained in the numerical analyses performed here are presented. In the same figure, scalar fields of flow velocity components are also presented. One can observe that a clockwise main recirculation region positioned near the geometric center of the cavity is obtained. In addition, when isothermal conditions are considered, secondary counterclockwise recirculation regions are also identified at the roof level, near the leeward corner, and at the corners of the ground level. These results are similar to numerical predictions obtained by Ghia et al. [12] and Liu et al. [19], who employed LES for a street canyon with unit aspect ratio and $\mathrm{Re}=12000$. Previous studies using RANS and $k-\varepsilon$ did not present the secondary recirculation regions owing to deficiencies associated with the turbulence model. Sini et al. [24] and Kim and Baik [15], by employing twodimensional $k-\varepsilon$ turbulence models, obtained a clockwise main recirculation region in the canyon cavity when isothermal conditions are considered. The scalar fields of flow velocity 
components obtained here are in agreement with predictions obtained by Liu et al. [19] under isothermal flow.

Table 2. Street canyon 2D: flow properties.

\begin{tabular}{ccc}
\hline \multirow{2}{*}{ Flow properties } & \multicolumn{2}{c}{ Flow conditions } \\
\cline { 2 - 3 } & Isothermal & Non-isothermal \\
\hline Reynolds number & 12000 & 12000 \\
\hline Prandtl number & - & 0.7 \\
\hline Schmidt number & 0.9 & 0.9 \\
\hline Turbulent Schmidt number & 0.9 & 0.9 \\
\hline Mach number & 0.16 & 0.16 \\
\hline Richardson number & - & 0.2 \\
\hline
\end{tabular}
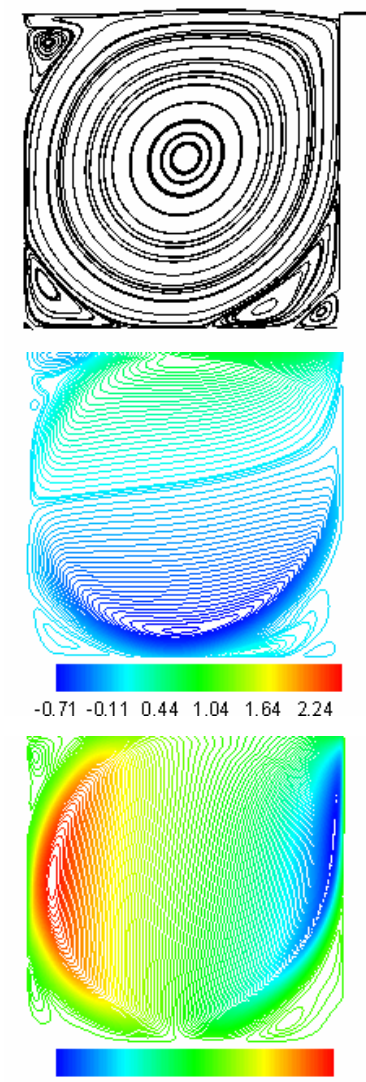

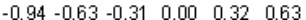
(a) no heating
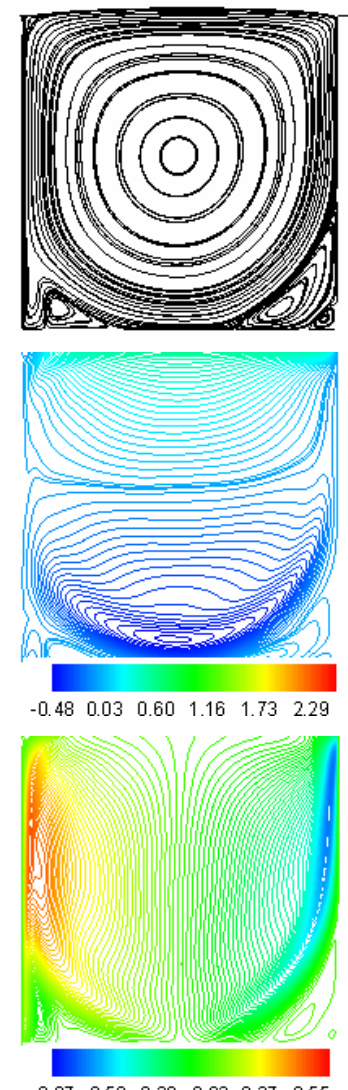

(b) upwind heating
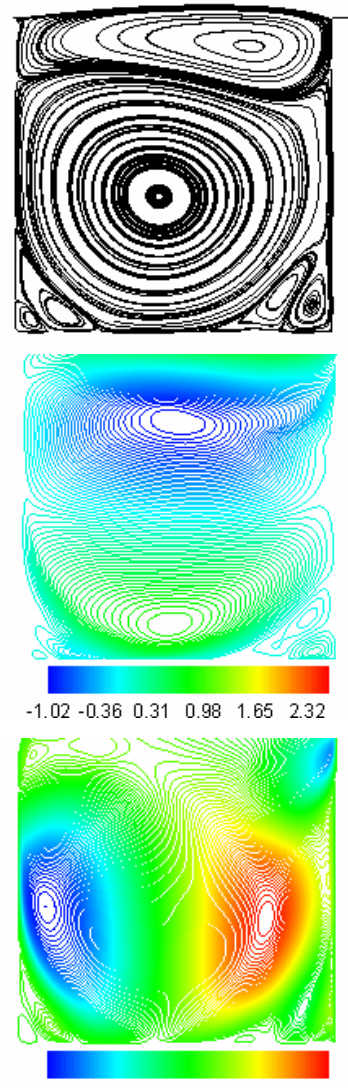

$\begin{array}{rllll}-0.90 & -0.59-0.28 & 0.03 & 0.34 & 0.65\end{array}$ (c) downwind heating
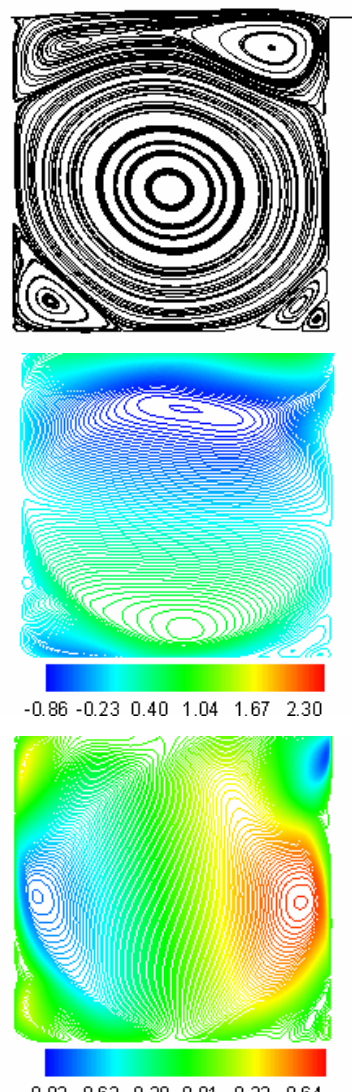

(d) bottom heating

Figure 2. Two-dimensional street canyon analysis - time average fields: streamlines (first row), flow velocity components $\mathrm{v}_{1}$ and $\mathrm{v}_{2}$ (second and third row, respectively).

The influence of the wall temperature over the flow field is evidenced when results are compared with predictions obtained using isothermal conditions. The flow field obtained when the upwind wall of the canyon is heated presents the same clockwise recirculation region observed previously. However, the upper vortex disappears and the size of the vortex at the left corner is slightly reduced. In addition, its location is shifted to the right. On the order hand, when the downwind wall of the canyon is heated, two main counterclockwise vortices 
show up, where the upper one presents a clockwise circulation. Secondary vortices at the ground-level corners are also observed in this case. When the bottom is heated, one can observe a flow structure similar to that obtained when the downwind wall is heated, however the upper vortex presents some instability and tends to split into two recirculations regions with clockwise rotation. Furthermore, the secondary vortex at the left corner is greater in the present case.

Scalar fields referring to temperature and dimensionless pollutant concentration obtained with the present numerical model are shown in Fig. 3, where average results are considered. As expected, the pollutant dispersion is confined to the canyon region owing to the geometric configuration of the canyon analyzed here.

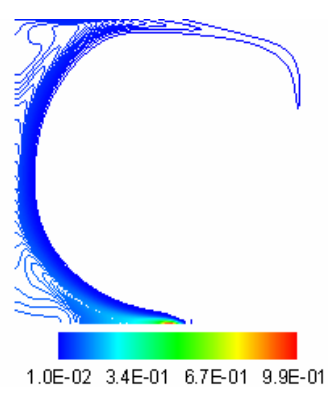

(a) no heating
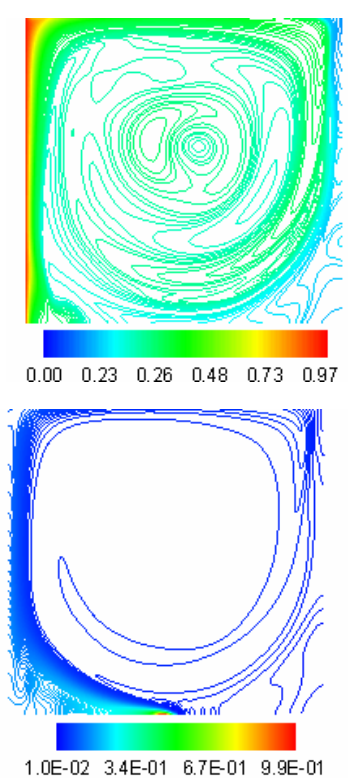

(b) upwind heating
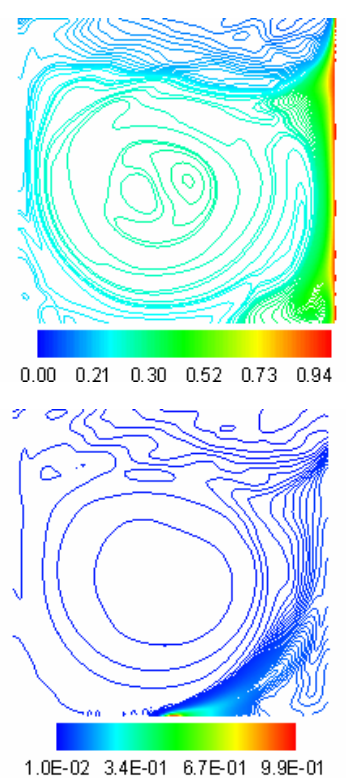

(c) downwind heating
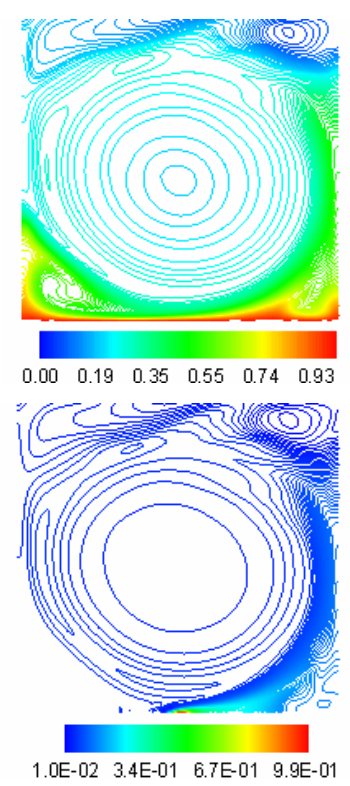

(d) bottom heating

Figure 3. Two-dimensional street canyon analysis - time average fields: temperature (first row) and pollutant concentration (second row).

\subsection{Pollutant dispersion between two-dimensional building models}

In order to analyze more realistic problems, the pollutant dispersion around buildings is simulated using two-dimensional models of street canyons formed by a pair of buildings with different geometric aspects. In the first configuration both buildings have the same height but the upstream building is wider than the downstream building while in the second configuration both buildings have the same width but the downstream building is higher than the upstream building. In the present application, the flow fields are complex due to flow phenomena such as separation and reattachment, which are observed over the upstream building of the street canyon and lead to strong interaction between the flow developed inside and outside the canyon cavity. In Fig. 4, the computational domain and boundary conditions adopted here are shown, where two different geometric configurations can be identified with their respective mesh configurations around the canyon region. The finite element meshes are constituted by 159925 and 279600 eight-node hexahedral elements, respectively, with $\Delta x_{E}=$ $0.002 \mathrm{~m}$, which is related to the smallest elements located near the building and ground sur- 
faces. In the canyon cavity $120 \times 120$ elements were adopted in the spatial discretization. Noslip boundary conditions are assumed on the building and ground surfaces. The pollutant is emitted from a point source positioned at the bottom of the canyons with an emission rate of $\mathrm{S}_{\mathrm{C}}=0.01 \mathrm{~m}^{3} / \mathrm{s}$ (see Fig. 4). Inflow boundary conditions are assumed according to the atmospheric boundary layer, which is reproduced considering an exponential distribution for the streamwise component of the flow velocity along the height of the computational domain.

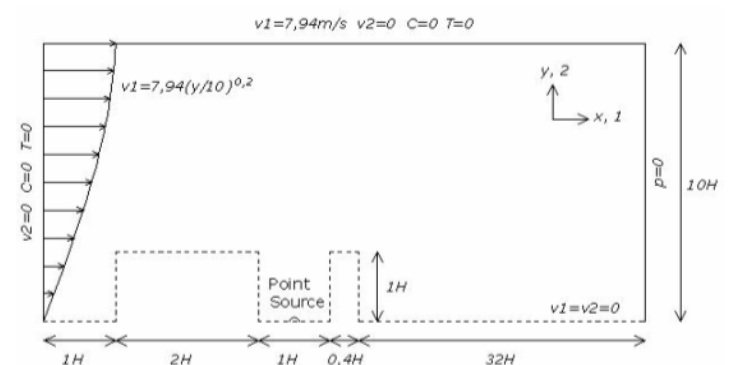

(a)

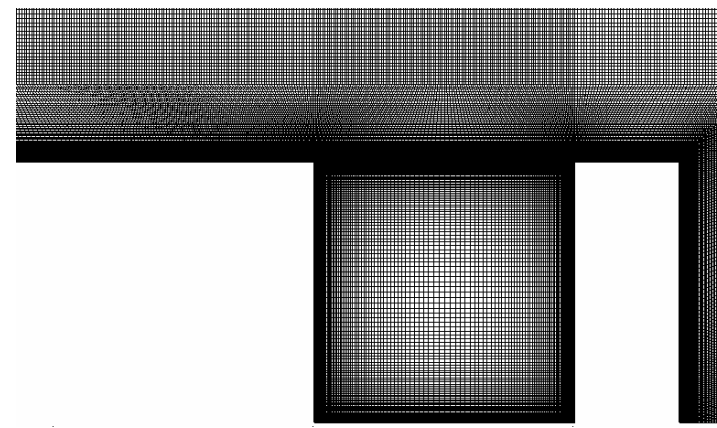

(c)

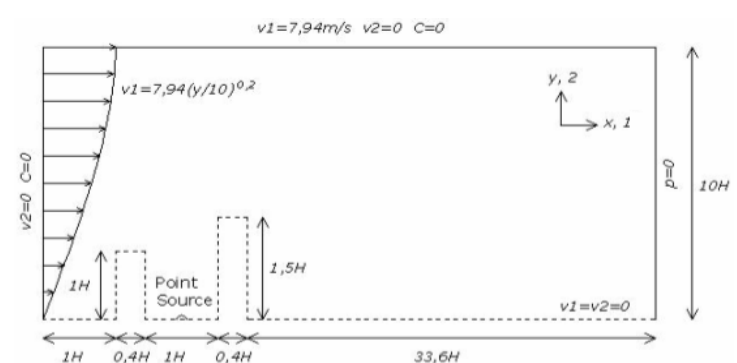

(b)

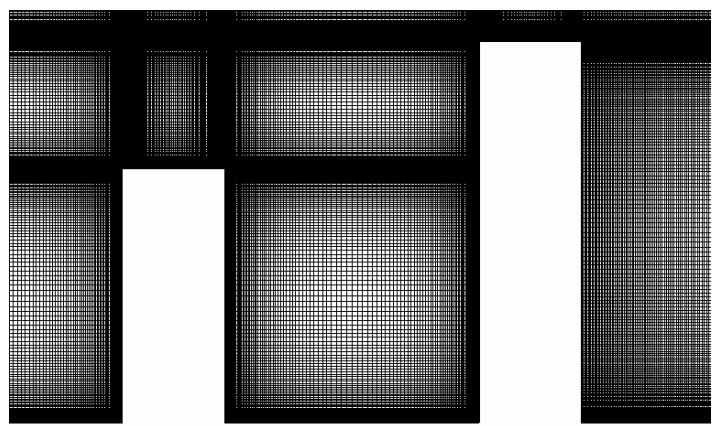

(d)

Figure 4. Two-dimensional building analysis - computational domain and finite element mesh: (a) and (c) configuration 1; (b) and (d) configuration 2.

Table 3. Two-dimensional building analysis: flow properties.

\begin{tabular}{cc}
\hline Reynolds number & 10000 \\
\hline Prandtl number & - \\
\hline Schmidt number & 0.7 \\
\hline Turbulent Schmidt number & 0.7 \\
\hline Mach number & 0.18 \\
\hline Richardson number & - \\
\hline
\end{tabular}

In Table 3, the flow properties utilized in the present simulations are reported. LES was adopted for turbulence modeling, where the dynamic and classical SGS models were utilized in the numerical analyses referring to configuration 1 and configuration 2, respectively. The Smagorinsky's constant Cs was set to 0.12 when the classical model was employed. The flow fields are started considering zero initial conditions for the flow variables and the time step adopted in the time integration process is $\Delta \mathrm{t}=2.5 \times 10^{-5} \mathrm{~s}$, which is obtained taking into account Eq. 34 with $\alpha=0.41$. The Reynolds number is calculated using the canyon width (W) and the flow velocity at $y=H$. The numerical simulations were performed up to $t=45 \mathrm{~s}$ and time average fields were obtained over the last $15 \mathrm{~s}$ of the present analyses. 


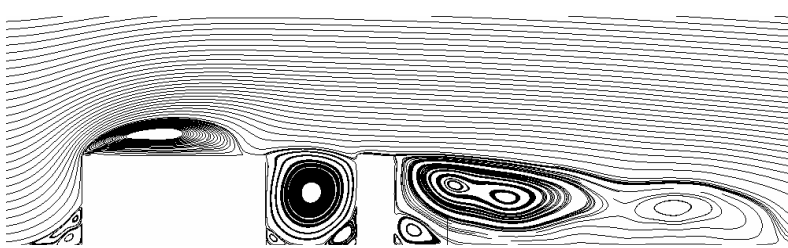

(a)

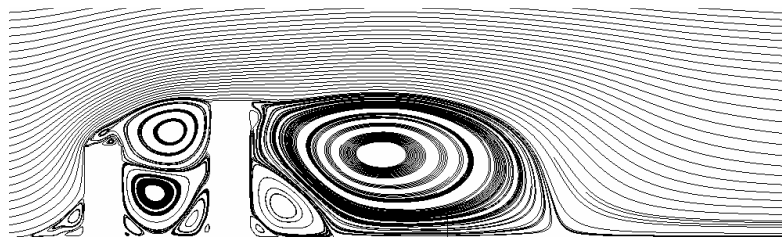

(c)

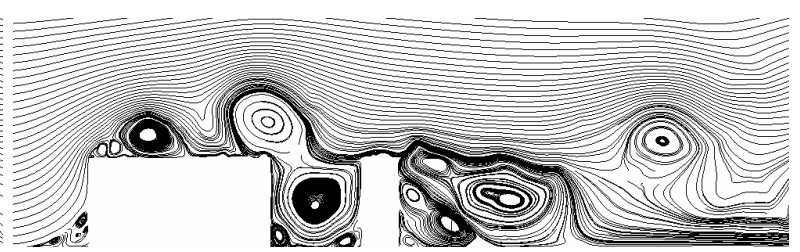

(b)

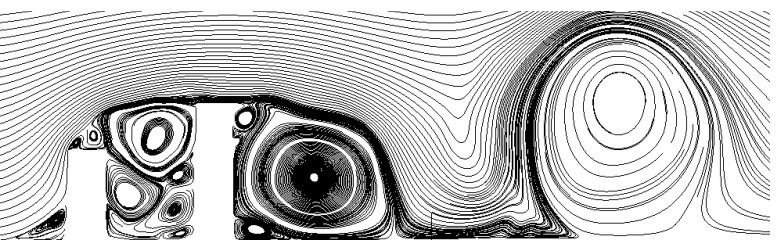

(d)

Figure 5. Two-dimensional building analysis: (a) and (c) time average streamlines; (b) and (d) instantaneous streamlines at $\mathrm{t}=45 \mathrm{~s}$.

Fig. 5 presents the time average streamlines obtained with the numerical model proposed in this work for the different configurations investigated here. One can notice that a recirculation zone is created above the upstream building of configuration 1 (see Fig. 5a), which reattaches before the corresponding trailing edge. Consequently, a clockwise recirculation zone is formed in the canyon cavity presenting a flow configuration very similar to that observed in the first investigation performed in this work when isothermal conditions were considered. The results related to configuration 2 (see Fig. 5c) show that two main recirculation regions with opposite directions are obtained in the canyon cavity and secondary vortices can be identified at the corners of the ground level. Instantaneous fields are also presented, where large vortices can be observed. These vortices are generated on the leading edge of the upstream building, which are carried by the flow and leads to strong interaction with the canyon flow. After the downstream building, a vortex trail is created with large vortices shed from the trailing edge of the building.

Time average scalar fields related to the flow variables in the street canyon are found in Fig. 6, where results referring to pressure, flow velocity components and pollutant concentration are presented. The predictions obtained here considering configuration 1 are in agreement with results obtained for street canyons with unit aspect ratio $(\mathrm{H} / \mathrm{W}=1)$.

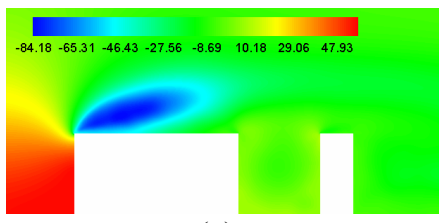

(a)

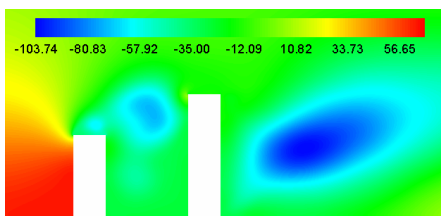

(e)

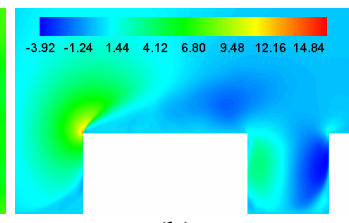

(b)

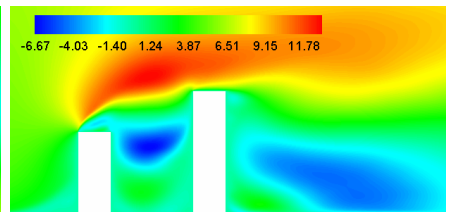

(f)

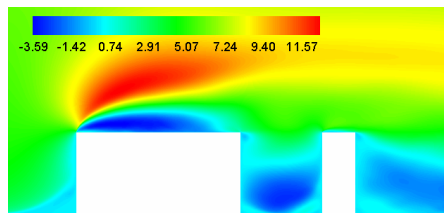

(c)

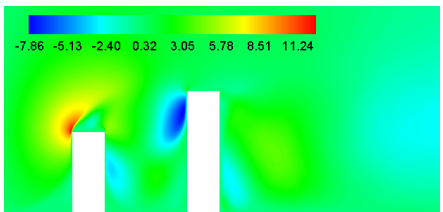

$(\mathrm{g})$

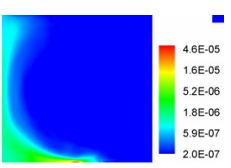

(d)

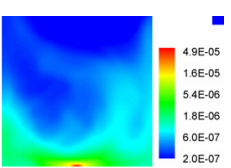

(h)

Figure 6. Two-dimensional building analysis - time average scalar fields: (a) and (e) pressure; (c) and (f) flow velocity component $\mathrm{v}_{1}$; (b) and (g) flow velocity component $\mathrm{v}_{2}$; (d) and (h) pollutant concentration. 


\subsection{Pollutant dispersion in three-dimensional urban area}

In the present analysis, a real application considering the evaluation of wind conditions and pollutant dispersion around a cluster of buildings is proposed, which is based on the studies carried out by Stathopoulos and Baskaran [26], who investigated the wind environmental conditions around a block of buildings using experimental and numerical techniques. A model of the downtown Montreal region was selected for this purpose, where the building models were assumed to have rectangular shape and details of the external surface were omitted. Since the investigations performed by Stathopoulos and Baskaran [26] were carried out considering incompressible flows without heat or mass transfer, a high point source and low linear sources of a pollutant are proposed in order to analyze the pollutant dispersion in this case. A schematic view of the computational domain utilized here and the mesh configuration in the region of the buildings are found in Fig. 7, where geometric information on the building models and boundary conditions adopted are indicated. The finite element mesh is constituted by 1268272 eight-node hexahedral elements, with $\Delta x_{E}$ about $0.2 \mathrm{~m}$, which is related to the smallest elements located near the buildings and ground surfaces. The positions of the point source and the linear pollutant sources, which approximately reproduce emission conditions observed under intense traffic of vehicles, are also shown. The pollutant sources are characterized with an emission rate of $\mathrm{S}_{\mathrm{C}}=0.01 \mathrm{~m}^{3} / \mathrm{s}$.

Table 4. Three-dimensional urban area: flow properties.

\begin{tabular}{cc}
\hline Reynolds number & $1.692 \times 10^{8}$ \\
\hline Prandtl number & - \\
\hline Schmidt number & 0.72 \\
\hline Turbulent Schmidt number & 0.72 \\
\hline Mach number & 0.18 \\
\hline Richardson number & - \\
\hline
\end{tabular}

Table 4 summarizes the flow properties characterizing the simulation conditions adopted in the present analysis, where an isothermal process is assumed. Turbulence is simulated considering LES and the classical Smagorisky's SGS model, where $\mathrm{C}_{\mathrm{S}}=0.10$ are utilized. The flow variables are started with zero initial conditions, where the time step is chosen taking into account Eq. 34 with $\alpha=0.80$, which leads to $\Delta \mathrm{t}=6.0 \times 10^{-4} \mathrm{~s}$. The Reynolds number is obtained considering the width of building $X$ and the flow velocity at the height of the same building (see Fig. 7). The numerical analysis was carried out up to $t=150 \mathrm{~s}$ and time average fields were obtained over the last $40 \mathrm{~s}$ of the time interval of the present simulation. 


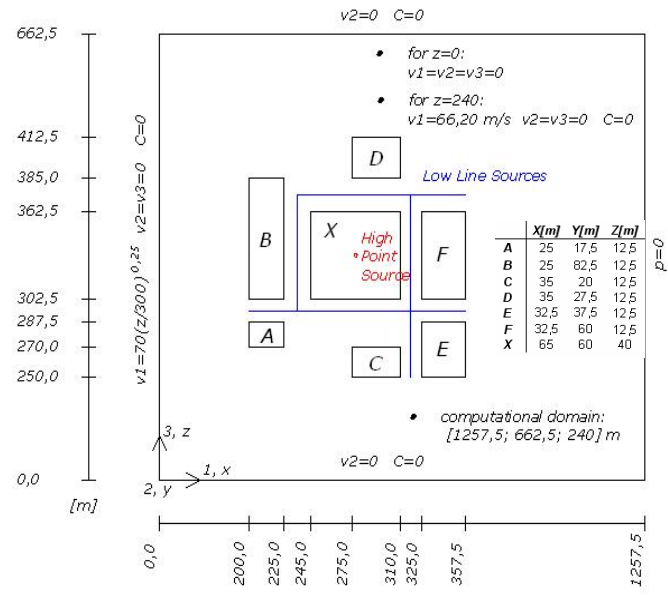

(a)

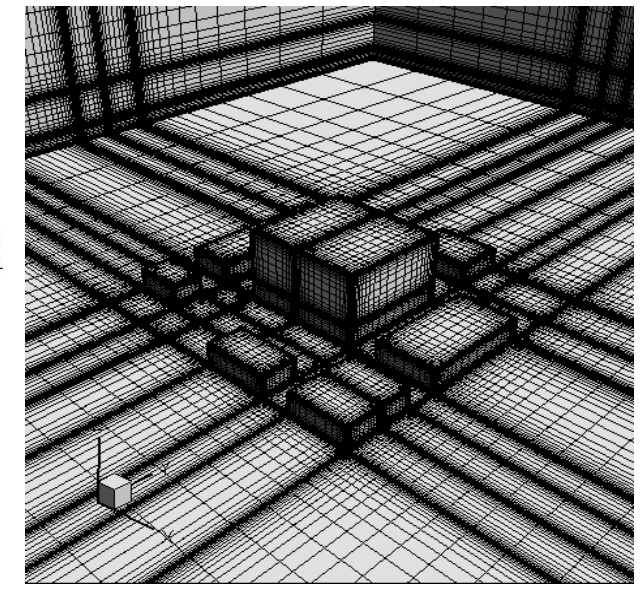

(b)

Figure 7. Three-dimensional urban area: (a) computational domain; (b) finite element mesh.

Time average streamlines obtained in the present analysis are shown in Fig. 8, where important flow phenomena such as horseshoe vortices can be observed. Two street canyons are formed upstream and downstream the highest building of the block configuration, where a recirculation zone can be noticed for the upstream canyon, which leads to the removal of the fluid by the lateral ends of the respective canyon.

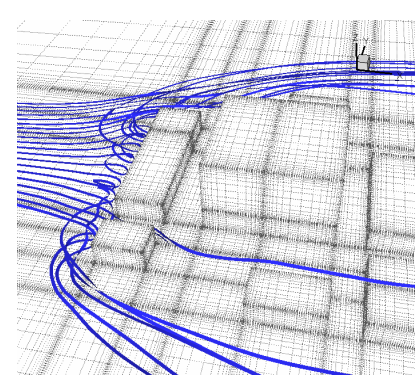

(a)

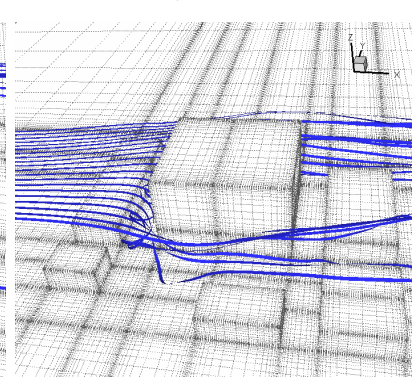

(b)

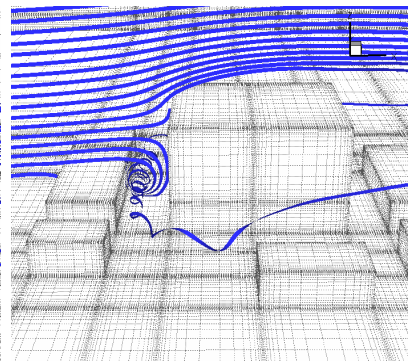

(c)

Figure 8. Three-dimensional urban area: time average streamlines at $\mathrm{z}=2.0 \mathrm{~m} \mathrm{(a),} \mathrm{z}=11.0 \mathrm{~m}$ (b) and $y=332.5 \mathrm{~m}$.

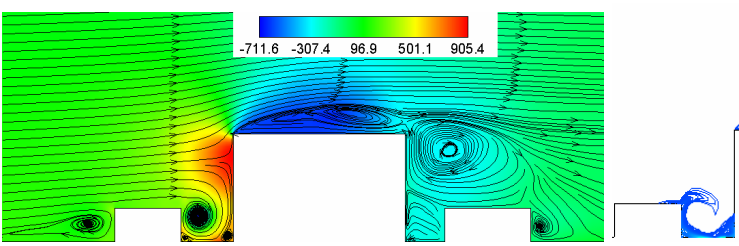

(a)

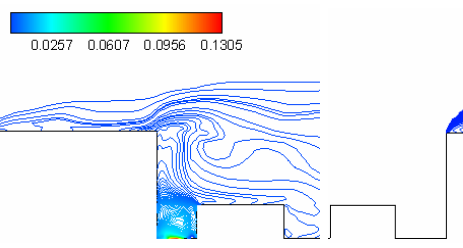

(b)

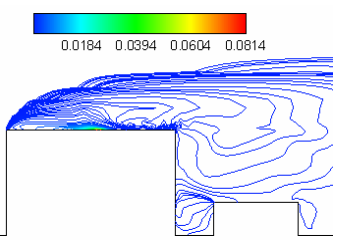

(c)

Figure 9. Three-dimensional urban area - time average fields on plane $y=332.5$ : pressure and streamlines (a), pollutant concentration considering low sources (b) and high source (c).

The flow circulation and the pollutant dispersion in the street canyons observed here, considering low and high sources, can be analyzed from Fig. 9, where time average fields are shown for the intermediate plane of the computational domain $(y=332.5 \mathrm{~m})$. One can notice that the recirculation zone above the downstream canyon is very similar to that obtained by other authors when similar relations between the building geometries are considered (see, for example, Ref. [2]). This flow characteristic plays an important role in the dispersion of pollutants in urban areas (see Figs. $9 \mathrm{~b}$ and c). 
In Fig. 10, an overview of the pollutant dispersion around the buildings in the case of the linear sources is presented taking into account horizontal planes corresponding to different levels of the computational domain. Pollutant concentration and pressure fields are shown with the respective streamlines, which are referred to the time average flow field obtained in the present analysis. One can observe that the pollutant concentration is low in the upstream canyon region due to the flow behavior observed in Fig. 8b. On the other hand, the pollutant concentration is high in the downstream canyon region and behind stagnated vortices formed in wake areas.

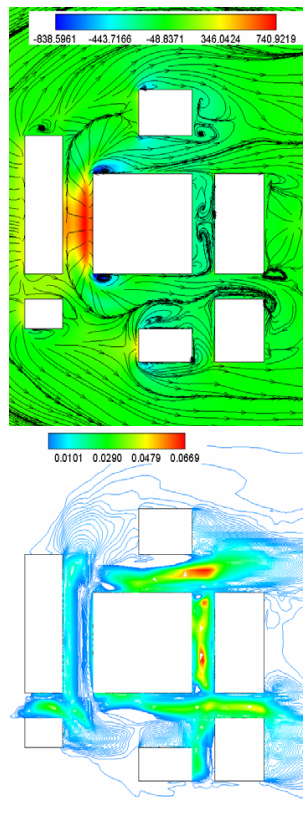

$\mathrm{z}=1.0 \mathrm{~m}$
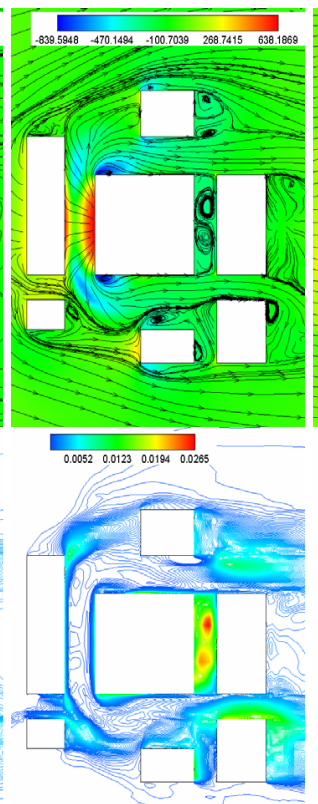

$\mathrm{z}=5.0 \mathrm{~m}$
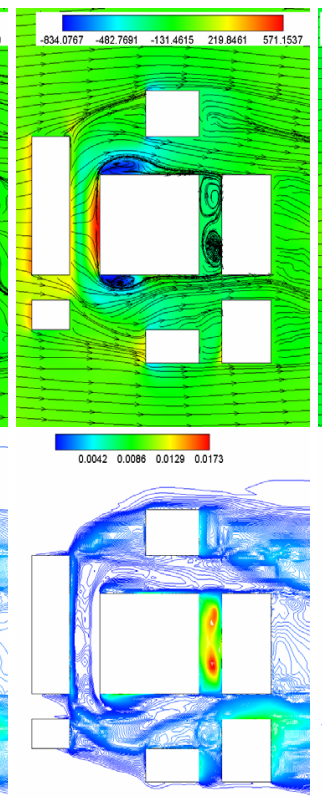

$\mathrm{z}=12.0 \mathrm{~m}$
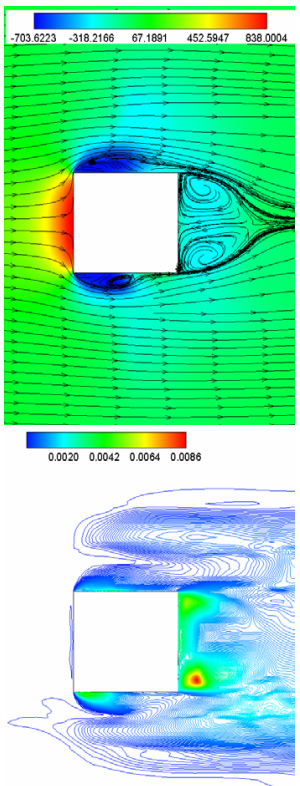

$\mathrm{z}=25.0 \mathrm{~m}$

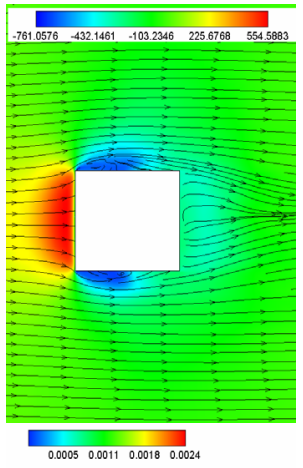

0.0005000110001800024

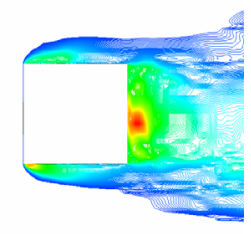

$\mathrm{z}=40.0 \mathrm{~m}$

Figure 10. Three-dimensional urban area: time average fields on plane xy considering different heights: pressure and streamlines (first row) and pollutant concentration considering low sources (second row).

\subsection{Efficiency evaluation of the parallel code}

In order to improve the computational efficiency of the numerical code developed in this work, all do loops were parallelized using OpenMP API, where the basic task employed here was to define shared and private variables.

The computational performance of the parallelization scheme adopted in this work may be verified using some parameters such as Speed-up ( $\mathrm{Sp}$ ) and Efficiency (Ep), which are evaluated as functions of the number of logical processors $(p)$ and number of finite elements. Two finite element meshes were utilized, which are referred to as model A, with 79600 elements, and model B, with 279600 elements. An intel core i7 2600 quad core processor with 8 Gb RAM was utilized in the tests presented here. In Fig.11, the Speed-up and Efficiency curves obtained in the present study are shown, where a very good performance can be noticed in the range $1 \leq \mathrm{p} \leq 4$. When additional logical processors are employed, one can observe that efficiency is significantly reduced. This behavior may be associated with the Hyper-Threading technology employed by intel processors. 

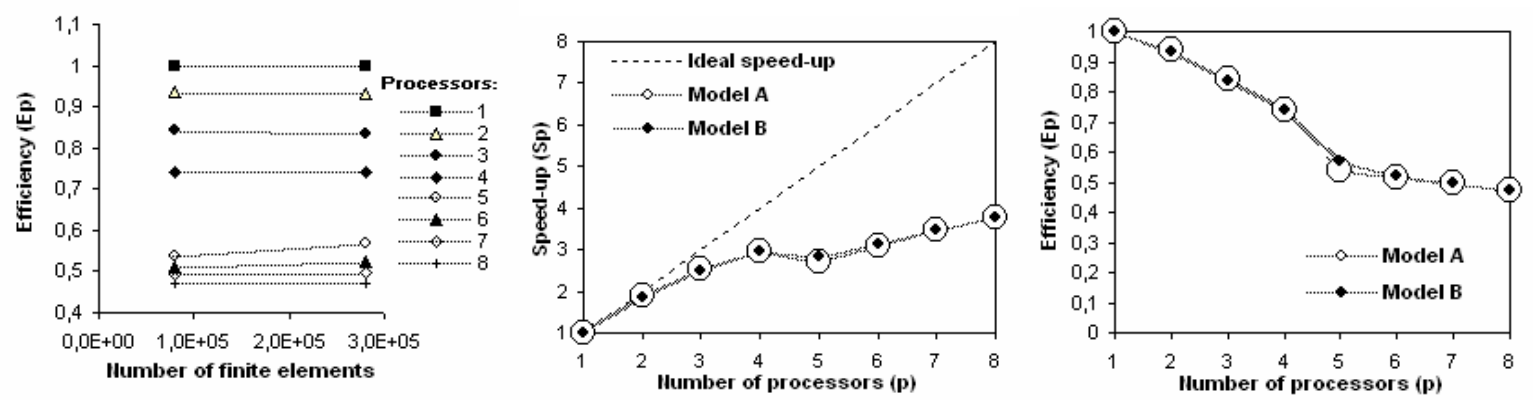

Figure 11. Computational performance obtained by the parallelization scheme utilized in this work. Speed-up: $\mathrm{Sp}=\mathrm{T}_{1} / \mathrm{T}_{\mathrm{p}}, \mathrm{T}_{1}$ - execution time corresponding to the sequential algorithm; $\mathrm{T}_{\mathrm{P}}$ - execution time corresponding to the parallel algorithm with $p$ logical processors; Efficiency: $\mathrm{Ep}=\mathrm{Sp} / \mathrm{p}$.

\section{CONCLUSIONS}

In the present work, a numerical model to investigate urban street canyon flows was presented, where a finite element formulation considering eight-node hexahedral elements with one-point quadrature was proposed. Governing equations for incompressible flows with heat and mass transfer were formulated taking into account the pseudo-compressibility hypothesis for explicit evaluation of the pressure field and LES for turbulence simulation. The present model was validated using idealized street canyon configurations under isothermal and non-isothermal conditions. Results obtained here demonstrated good agreement with predictions reported by other authors utilizing experimental and numerical methods. Applications involving street canyons formed between two-dimensional building models were also analyzed, where flow phenomena such as separation/reattachment and impingement were simulated. Finally, a realistic problem was proposed where an urban region was reproduced considering a typical geometric configuration of buildings and street canyons found in large cities. The flow characteristics observed in the street canyons reproduced well the recirculation pattern and the pollutant dispersion usually verified in those geometric configurations. A good performance was also obtained in the efficiency evaluation of the parallelization technique adopted in this work. For future works, a model to consider chemical reactions of the pollutants should be implemented in order to improve the numerical description of the physical phenomena observed in street canyon flows.

\section{Acknowledgements}

The authors would like to thank CNPq (Brazilian council of research) for the financial support. 


\section{REFERENCES}

[1] Assimakopoulos, V. D, AP Simon, H. M., Moussiopoulos, N., 2003. A numerical study of atmospheric pollutant dispersion in different two-dimensional street canyon configurations. Atmospheric Environment, vol. 37, pp. 4037-4049.

[2] Baik, J.-J., Kim, J.-J., Fernando, H.J.S., 2003. A CFD model for simulating urban flow and dispersion. Journal of Applied Meteorology, vol. 42, pp. 1636-1648.

[3] Belytschko, T., Ong, J.S.-J., Liu, W.K., Kennedy, J.M., 1984. Hourglass control in linear and nonlinear problems. Computer Methods in Applied Mechanics and Engineering, vol. 43, pp. 251-276.

[4] Braun, A.L., 2007. Simulação Numérica na Engenharia do Vento Incluindo Efeitos de Interação Fluido-Estrutura. D.Sc. Thesis, PPGEC/UFRGS, Porto Alegre, Brasil.

[5] Braun, A.L., Awruch, A.M., 2009. Aerodynamic and aeroelastic analyses on the CAARC standard tall building model using numerical simulation. Computers and Structures, vol. 87, pp. 564-581.

[6] Ca, V.T., Asaeda, T., Ito, M., Armfield, S., 1995. Characteristics of wind field in a street canyon. Journal of Wind Engineering and Industrial Aerodynamics, vol. 57, pp. 63-80.

[7] Cheng, W.C., Liu, C-H., 2011. Large-eddy simulation of turbulent transports in urban street canyons in different thermal stabilities. Journal of Wind Engineering and Industrial Aerodyanmics, vol. 99, pp. 434-442.

[8] Chorin, A.J., 1967. A numerical method for solving incompressible viscous flow problems. Journal of Computational Physics, vol. 2, pp. 12-26.

[9] Christon, M.A., 1997. A domain-decomposition message-passing approach to transient viscous incompressible flow using explicit time integration. Computer Methods in Applied Mechanics and Engineering, vol. 148, pp. 329-352.

[10] Findikakis, A.N., Street, R.L., 1982. Mathematical description of turbulent flows. Journal of the Hydraulics Division - ASCE, vol. 108, pp. 887-903.

[11] Germano, M., Piomelli, U., Moin, P., Cabot, W.H., 1991. A dynamic subgrid-scale eddy viscosity model. Physics of Fluids, vol. A3, pp. 1760-1765.

[12] Ghia, U., Ghia, K.N., Shin, C.T., 1982. High-Re Solutions for Incompressible Flow Using the Navier-Stokes Equations and a Multigrid Method. Journal of Computational Physics, vol. 48, pp. 387-411.

[13] Kastner-Klein, P., Plate, E.J., 1999. Wind-tunnel study of concentration fields in street canyons. Atmospheric Environment, vol. 33, pp. 3973-3979.

[14] Kawahara, M. e Hirano, H., 1983. A finite element method for high Reynolds number viscous fluid flow using two step explicit scheme. International Journal for Numerical Methods in Fluids, vol. 3, pp. 137-163.

[15] Kim, J-J and Baik, J-J., 1999. A numerical study of thermal effects on flow and pollutant dispersion in urban street canyons. Journal of Applied Meteorology, vol. 38, pp. 12491261.

[16] Li, X.X., Koh, T.Y., Britter, R., Liu, C.H., Norford, L.K., Entekhabi, D., Leung, D.Y.C., 2009. Large-eddy simulation of flow field and pollutant dispersion in urban street canyons under unstable stratification. In: Proceeding of the 7th International Conference on Urban Climate (ICUC-7), Yokohama, Japan.

[17] Li, X.X., Liu, C.H., Leung, D.Y.C., Lam, K.M., 2006. Recent progress in CFD modelling of a wind field and pollutant transport in street canyons. Atmospheric Environment, 
vol. 40, pp. 5640-5658.

[18] Lilly, D.K., 1992. A proposed modification of the Germano subgrid-scale closure method. Physics of Fluids, vol. 4, pp. 633-635.

[19] Liu, C.-H., Barth, M.C., Leung, D.Y.C., 2004. Large-eddy simulation of flow and pollutant transport in street canyons of different building-height-to-street-width ratios. Journal of Applied Meteorology, vol. 43, pp. 1410-1424.

[20] Madalozzo, D.M.S., 2012. Simulação Numérica da Dispersão de Poluentes em Zonas Urbanas considerando Efeitos Térmicos. M.Sc. Dissertation, PPGEC/UFRGS, Porto Alegre, Brasil.

[21] Nicholson, S.E., 1975. A pollution model for street-level air. Atmospheric Environment, vol. 9, pp. 19-31.

[22] Pavageau, M., Schatzmann, M., 1999. Wind tunnel measurements of concentration fluctuations in an urban street canyon. Atmospheric Environment, vol. 33, pp. 3961-3971.

[23] Sakakibara, Y., 1996. A numerical study of the effect of urban geometry upon the surface energy budget. Atmospheric Environment, vol. 30, pp. 487-496.

[24] Sini, J.-F., Anquetin, S., Mestayer, P.G., 1996. Pollutant dispersion and thermal effects in urban street canyons. Atmospheric Environment, vol. 30, pp. 2659-2677.

[25] Smagorinsky, J., 1963. General circulation experiments with the primitive equations I. The basic experiment. Monthly Weather Review, vol. 91, pp. 99-164.

[26] Stathopoulos, T., Baskaran, A., 1996. Computer simulation of wind environmental conditions around buildings. Engineering Structures, vol. 18, pp. 876-885.

[27] Vardoulakis, S., Fisher, B.E., Pericleous, K., Gonzalez-Flesca, N., 2003. Modelling air quality in street canyons: A review. Atmospheric Environment, vol. 37, pp. 155-182.

[28] Xie, X., Huang, Z., Wang, J., Xie, Z., 2005. The impact of solar radiation and street layout on pollutant dispersion in street canyon. Building and Environment, vol. 40, pp. 201-212.

[29] Xie, X., Liu, C-H., Leung, D.Y.C., Leung, M.K.H., 2006. Spatial distribution of trafficrelated pollutant concentrations in street canyons. Atmospheric Environment, vol. 40, pp. 6396-6409.

[30] Xie, S., Zhang, Y., Qi, L., Tang, X., 2003. Spatial distribution of traffic-related pollutant concentrations in street canyons. Atmospheric Environment, vol. 37, pp. 3213-3224. 